\title{
Cooperative Learning, Responsibility, Ambiguity, Controversy and Support in Motivating Students
}

\author{
Ronald Brecke, PhD \\ Professor of Political Science \\ Park University \\ Jacy Jensen \\ Park University
}

This paper argues that student motivation is nurtured more by intrinsic rather than extrinsic rewards. Rather than relying on grades alone to stimulate students, this paper explores how engendering a natural critical learning environment can give students a sense of ownership in their own learning and lead to their commitment to that learning. We examine uses of cooperative learning, shared responsibility, ambiguity, controversy and support in student motivation.

\section{Introduction}

The question of student motivation in the college classroom often arises and is neither a casual nor an idle question. Important material delivered by an exceptional scholar may fall on fallow ground if students are not motivated enough to cultivate it. In his book "What the Best College Teachers Do", Ken Bain recounts the scholarship regarding student motivation. Extrinsic rewards (grades, for example) eventually fail to keep students stimulated. Such extrinsic rewards can come to be seen by students as manipulative or unattainable and, thus, less significant in terms of maintaining student interest. Intrinsic rewards, such as constructive criticism appear to be more effective in keeping students involved (3234). Using fundamental, "big" questions can also be used as a kind of intrinsic reward (38).

Cooperative learning through group projects may also provoke students to strive. "In a cooperative atmosphere, students are motivated out of a sense of obligation; one ought to try, contribute, and help satisfy group norms" (Biehler and Snowman 7; see also Boyer Commission 19). Motivation is also sparked by giving students shared responsibility with the instructor for achieving goals (Teeples and Wiebman 4). Students usually have some intentions when entering a course, which faculty should be open to listening to and, when appropriate, incorporating into the course.

Felder and Brent speak of students who take a "deep approach" to learning. These students "routinely try to relate course material to other things they know, look for applications, and question conclusions" (2; see also Bain 40). Certain approaches taken in class can tap into this outlook, particularly using topics that may raise questions without answers.

Combining these ideas on student motivation provides some methods to help students achieve and maintain interest not only in a given course, but in other courses that can be connected by students developing

The approach is one that reflects "education by inquiry" where students and instructors share in the process of discovery and where "students can become active rather than passive learners."

their critical thinking abilities. The approach is one that reflects "education by inquiry" where students and instructors share in the process of discovery and where "students can become active rather than passive learners" (Boyer Commission 24). 


\section{Cooperative Learning and Shared Responsibility}

In addition to providing a way to divide the labor of a project, working in groups allows for each student's knowledge of the subject to be an important aspect of project completion, and therefore all the students must become engaged. The added pressure from their peers gives students more motivation to meet or even exceed the expectations of a given assignment. Members of the team provide mutual encouragement and assistance, thus making for a more positive learning atmosphere, rather than merely a competitive one.

In evaluations of Professor Brecke's Political Science courses over the last five years, students have consistently indicated that sections of courses utilizing cooperative learning provided insights and interest that lectures alone did not. Boyer points out that learning should be active, not passive: "It is a process of discovery in which the student is the main agent, not the teacher" (150-151, 155; see also Boyer Commission 24).

Along with the increased peer pressure, using teamwork is a good way to approach the subject in a new and different way, which maintains interest and motivation. Cooperative learning is accessible in all learning situations; thus, it can help to improve student motivation (Biehler and Snowman 9-11).

By working in groups, students help each other succeed and therefore build their own self-esteem. The cooperative learning atmosphere gives teachers an opportunity to

Along with the increased peer pressure, using teamwork is a good way to approach the subject in a new and different way, which maintains interest and motivation.

allow students to establish policies and classroom procedures as well. This empowers the students, which creates a positive learning environment for all. When working cooperatively as a team, all the team members earn the same reward. Thus, these positive aspects of cooperative learning lead to increased intrinsic motivation and better leadership skills for the students.

Group projects must be associated with the overall learning objectives of the course and the expectations of the students. Here the professor needs to listen to the students when designing group projects. One beneficial alternative would be to offer multiple types of projects and allow students to determine which are most appropriate. Students have a stake in each course they take and should be given some say in what the course will provide. This attaches a sense of responsibility for the course to the student as well as to the professor. Pride of ownership can successfully motivate, but input from the students can provide even more than just motivation. Once students assume partial responsibility it becomes incumbent upon them to fix problems as they arise and not just complain about them.

If a project develops some snags, students will have the incentive to produce solutions. For example, Dr. Brecke often asks groups of students to play the role of the ultimate decision maker at the Food and Drug Administration. The problem they face is that some common ailment (colds, arthritis, etc.) can be cured, but that the cure produces death for no known reason in some percentage of those who take it. Students are asked to find an acceptable death rate that would permit them to release the cure to the public. No other information is provided to the students. Students are then faced with differing points of view not only over death rates, but also over whether warning labels should be included, whether the cure should be prescription only, and whether age limits should be placed on the use of the cure. Students work through these problems as the encouragement of critical thinking, the benefit of shared responsibility, and the emphasis on studentdeveloped solutions offer them an incentive other than just grades. . Learning what is not possible is just as important as learning what is possible, and therefore a project that perhaps overreaches should not be rejected out of hand. Problem solving of this nature can produce critical thinking and confidence. (Also see the case study in Appendix A) 


\section{Ambiguity and Controversy}

Often we are so concerned with communicating what a particular field of study knows that we miss the importance of sharing that that is not known, or at least that which is not known with certainty. Ambiguity plays a significant role in stimulating student interest in and retention of material. Uncertainty also gives spark to critical thinking that, when developed, is a motivational factor itself. Ambiguity requires that a higher level of learning than rote memory be engaged. If there is no single answer to a problem, students realize that a mere recitation of what the book or lecture says is inadequate. Together, uncertainty and critical thinking give the student a sense of responsibility for their learning as well.

Bain suggests that the "big questions" underlying many topics can be used to give students the ability to make linkages between topics, courses, and even fields of study (38). He argues that creating a "natural critical learning environment" is the best way to encourage student learning and motivation. This environment is challenging yet supportive; it is an

\author{
Ambiguity requires that a \\ higher level of learning than \\ rote memory be engaged. If \\ there is no single answer to \\ a problem, students realize \\ that a mere recitation of \\ what the book or lecture \\ says is inadequate. \\ Together, uncertainty and \\ critical thinking give the \\ student a sense of \\ responsibility for their \\ learning as well.
} environment where "people learn by confronting intriguing, beautiful, or important problems, authentic tasks that will challenge them to grapple with ideas, rethink their assumptions, and examine their mental models of reality" (18).

Inserting uncertainty into the course material is not all that tricky. It takes a somewhat stout heart, however, as the professor must overcome the impulse to maintain control through, if nothing else, having the answers. Faculty members must have the confidence in themselves to reveal to students that they are not the oracle. But this revelation itself may spur intellectual activity on the part of the students as they are forced to provide answers for themselves. Faculty members are, in Bain's words: "empowering... students to find their own creativity" (2).

The American Association of Colleges and Universities found in its study Integrative Learning: Opportunities to Connect that integrative learning-helping students connect across courses, fields and time-can be assisted by presenting students with contradiction. Moreover, if these presentations are about real-world problems, and seek to apply several areas of knowledge to those problems, students are better prepared to face similar problems in their own lives (1).

If learning is best incubated in an atmosphere of challenge and support, then what better way to foster that atmosphere than for professors to join their students in discovery? Some very practically minded students (and professors) may balk at such an approach. But even the most practical will gain insight into solving practical problems by examining problems that evolve into uncertainty. It is the journey, not the destination that counts. Many seek post-secondary educations that will supply them with given solutions to given problems. Much of the real world, however, will not present our graduates with "given" problems. The realization of this is the basis for suggestions made in the Boyer Report (17, 20-21) and in Boyer's own work (Chs.17, 20 and 21) that students should be engaged by postsecondary education to see the forest for the trees. Students should be awakened, he argues, to the interconnections in life and become foxes rather than hedgehogs. Many of the problems students will face may not fit neatly into prearranged forms. Instead, many problems will be unique and will require adaptability.. Solutions, unless carefully crafted to the situation at hand, may contradict goals in other areas, or may even create the unintended result of creating new (and perhaps greater) problems. Facing such situations may overwhelm students who have not had the experience of confronting ambiguity. 
If students are comfortable with ambiguity and its attendant critical thinking, they will not be put in a panic by problems that appear to only have either/or solutions, neither of which will lead to the highest degree of success. False dichotomies may be exposed for what they are by those who have been faced with a learning process that encourages solid reasoning about alternative approaches.

The introduction of controversy to course material can give students (and faculty) practice in the world of ambiguity. Controversy in a field of study doesn't necessarily mean that some answers aren't better than others, but that there are challenges to answers that need to be grappled with intellectually. Darwin versus Creationism in biology, Friedman versus Keynes in economics, and ideological versus socio-economic explanations for voting patterns are all examples of such controversies. These controversies provide the opportunity to explore subjects that go beyond doctrines. This might also lead to getting beyond what might be false dichotomies. Moreover, by exposing students to such controversies it naturally follows that discussions of the various influences each of the sides would have on other fields of study and society in general would ensue. This gives each field the incentive and occasion to link

The introduction of controversy to course material can give students (and faculty) practice in the world of ambiguity. Controversy in a field of study doesn't necessarily mean that some answers aren't better than others, but that there are challenges to answers that need to be grappled with intellectually.

itself with a much broader spectrum. It would also make the material more relevant to the lives of the students, which encourages them to take more responsibility for their learning. (See the case study in Appendix A.)

Using controversy establishes a course as one that encourages what Bain calls "deep learners". These are people who "respond primarily to the challenge of mastering something, of getting inside a subject and trying to understand it in all of its complexity" (40; see also Felder and Brent 2 ). These students will respond to material that asks the bigger questions and will attempt to put course material into a larger context from which they can see connections to other material, classes and subjects, and controversy leads to these larger questions.

\section{Support}

Many students have had experience with professors who, at the very least, appear aloof and even disengaged. They don't relate to the student very well and therefore tend to be unsuccessful as teachers (though they may be very fine researchers). These professors offer little in feedback, constructive criticism or support. It is not that they don't have high standards, but rather that they have high standards for which there is only one measure submitted: the final grade. While they have high standards, their expectations for students are low.

The "natural critical learning environment" is one where students are challenged yet supported. This environment creates conditions where students "believe that their work will be considered fairly and honestly; and try, fail, and receive feedback from expert learners in advance of and separate from any summative judgment of their effort" (Bain 18, 99-103). This environment is a direct challenge to that of the disengaged expert.

To create such an environment, instructors must first trust that students have the ability and willingness to become critical thinkers and learners. If they don't believe students can handle challenges, that they don't want to go beyond rote memory, and that they aren't prepared to take some responsibility for their own education, then the odor of failure has already begun to seep in. It would be interesting to know for those instructors who do not have this trust what exactly motivated them to become post-secondary teachers. 
The atmosphere in the classroom should include shared expectations. While asking students what their expectations are in the first meeting may provide some broad answers, it is more helpful to delay such inquiries until the completion of several sessions. During these sessions you should explain your commitment to the course, the integrity of the learning experience and what challenges lie ahead. After students become familiar with the basic course material you will find that their judgments as to what they would like to see coming out of the course are more focused and attuned within the parameters of the course material.

A course should use what might be called developmental assignments. Rather than presenting students with discrete exercises that are handed in, graded, returned and are replaced with a new assignment, developmental assignments are those that students work on over a period of time with several opportunities for feedback. Portfolio-based courses are useful in furthering these ideas. These assignments need not be semester-long, but they should provide students with the opportunity to learn as they go along. Students respond to high expectations linked with such assignments because they judge that the teacher "believed the student had the capacity to benefit from advice" (Bain 77). That is, not only will developmental assignments create high expectations and high standards draw students to improve their performance, but these assignments will also let them know that the professor has confidence in their ability to improve. This isn't simply massaging their self-esteem by making everyone feel good, but a true intellectual endeavor toward discovery and mastering of material as well as discovery of their own interests. This gives students an opportunity to feel comfortable even when uncertainty may lie in their path.

\section{Conclusion}

Motivation in the classroom, and life in general, must be authentic and therefore related to what students see as interesting and worthwhile. When students begin challenging themselves and asking their own questions, it is clear that they will go out into the world with understanding, and perhaps even a little skepticism, that will promote an ability to

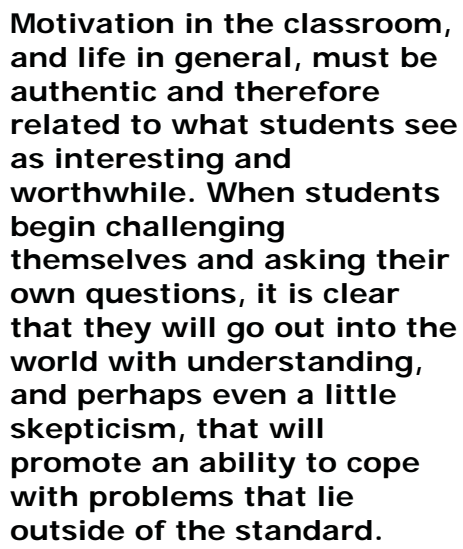

cope with problems that lie outside of the standard. The approaches discussed above also help develop critical thinking abilities, a key element in success in the modern world. After all, students will be facing opportunities and situations to which we don't even have the questions yet, much less the answers. By enriching their learning experiences through giving them responsibility, curiosity, as well as confidence in their own abilities, students will be prepared for those opportunities.

\section{Works Cited}

Bain, Ken. What the Best College Teachers Do. Cambridge, MA: Harvard University Press, 2004.

Biehler, Robert and Jack Snowman. "Motivation." Houghton Mifflin's Project-Based Learning Space. 19 March, 2007 <http://college.hmco.com/education/ $\mathrm{pbl} / \mathrm{tc} /$ motivate. html>
Boyer Commission. "Reinventing Undergraduate Education: A Blueprint for America's Research Universities." 1998 http://naples.cc.sunysb.edu/Pres/boy er.nsf/ 673918d46fbf653e852565ec0056ff3e /d955b61ffddd590a852565ec005717 ae/\$FILE/boyer.pdf> 
Boyer, Ernest. The Undergraduate Experience in America. New York: Harper and Row, 1987.

Felder, Richard M. and Rebecca Brent. "Dealing with Student Background Deficiencies and Low Student Motivation." FAQs-IV. 11 Jan. 2007

$<$ http://www.ncsu.edu/felderpublic/Columns/FAQs-4.html>
Teeples, Ronald and Harvey

Wiebman. "The Critical Match

Between Motivation to Learn and

Motivation to Teach." The

Professional \& Organizational

Development Network in Higher

Education. $11 \mathrm{Jan}$.

2007<http://oira.syr.edu/cstl2/Home /Teaching\% 20Support/Resources/Su bscriptions/POD/V9/v9>.

Brecke is a professor of Political Science at Park University. He has been at Park University for twenty-five years. Previous written work includes "A Republic If You Can Keep It" published by Lexington Books in 2000.

Jensen is currently working on her Public Administration Degree at Park University. She is very involved in her church community and holds a part-time position as a Teacher Associate for the North Kansas City School District. Upon completing her undergraduate degree, Jensen will pursue a Master's Degree in Public Health. 
Appendix A: Interdisciplinary Case Study

Professors J ohn Lofflin (J ournalism) and Ron Brecke (Political Science) have successfully used these approaches in several interdisciplinary courses which covered topics such as covering reporting and elections and economic development in downtown Kansas City. Students from both disciplines participated. In each case, assignments were made that required cooperative efforts on the part of small groups. For example, in the course on reporting and elections, students were to prepare content analysis of various newspapers and interpret the type of story it was and detect any bias that may have been present.

Ambiguity and controversy were easily introduced in these courses. Questions were raised as to why certain sections of Kansas City received more redevelopment funds than others. Problems of how journalism should be presented to enhance citizenship during elections were examined. All of this was done with the expectation that we were all learning together. While various reading resources were utilized, much of the headway made during the course was based upon the students' critical thinking about events as well as theories.

Both professors scrutinized the outcomes of these courses in comparison to courses that were taught by them in a more traditional fashion such as "Reporting", "Campaigns and Elections", and "State and Local Government". While both see the need to improve upon their interdisciplinary and team teaching skills, they saw an overall improvement with the quality of the thinking by the students in these interdisciplinary courses over more traditional courses. They were also both surprised that some of the goals they had set for the courses were not achieved but that others had been gained that were not intended or predicted. 